0.96. Overall survival rates of $2^{\text {nd }}$ line bDMARD at 12,24 and 36 months was respectively $91 \%, 76.4 \%$ and $72.1 \%$. Among the patients receiving second biologic agent, $30.4 \%$ patients ( 24 cases) achieved either low disease activity (LDA) or remission. On average 38 weeks [14 - 96] were needed to reach that therapeutic target. In fact, $27.8 \%$ of the TNFi vs. $40 \%$ of the non TNFi patients achieved LDA $(p=0.277)$. Second biotherapy was withdrawn in $16.7 \%$ of the cases of TNFi group vs. $20 \%$ of the non TNFi group ( $p=0.718$ ). Moreover, no significant difference has emerged between the TNFi and the non-TNFi patients when comparing time to biotherapy discontinuation (15.8 months vs. $20.9 ; p=0.11$ )

Conclusion: In our study, no significant difference was found between TNFi and non-TNFi switcher in RA. But, treatment strategy after first bDMARD failure is still controversial. Further studies have to be done to get the most beneficial strategy in RA.

Disclosure of Interests: None declared

DOI: 10.1136/annrheumdis-2021-eular.3871

\section{AB0239 PERSISTENCE TO BIOLOGICAL DMARDS TNF INHIBITORS VS BIOLOGICAL DMARDS NOTNF INHIBITORS AFTER FAILURE TO SYNTHETIC CONVENTIONAL DMARDS IN RA PATIENTS TREATED IN STANDARD CLINICAL PRACTICE}

B. Hernández-Cruz ${ }^{1}$, P. Muñoz Reinoso ${ }^{2}$, I. García Hernández ${ }^{3}$, G. Jurado Quijano $^{3}$, L. Fernández de la Fuente Bursón ${ }^{3}$, I. M. Fernández-Maeztu

Palacín $^{3}$, A. Fernández Reboul Fernández ${ }^{3}$, D. Ruiz-Montesinos ${ }^{3}$, J. J. Pérez Venegas ${ }^{3} .{ }^{1}$ Hospital Universitario Virgen Macarena, Rheumatology, Seville, Spain; ${ }^{2}$ Hospital Universitario Virgen Macarena, Rheumatologyy, Sevilla, Spain; ${ }^{3}$ Hospital Universitario Virgen Macarena, Rheumatology, Sevilla, Spain

Background: There are no RA response predictors for our patients. The decision to initiate a first biological depends on multiple factors such as rheumatologist experience, clinical characteristics of the patient and health system. What is clear is that the best strategy is T2T.

Objectives: To know the clinical characteristics and persistence of the first biological DMARD in patients receiving bDMARDS TNF inhibitors vs DMARDs aimed at other targets.

Methods: A observational cohort of adult RA patients (ACR/EULAR 2010) in a rheumatology department of a third-level university hospital. All patients were treated with a first bDMARD marketed in Spain, from 2010 to December 2020 and prescribed according to product data sheet. Biological drugs were divided into TNF inhibitors drugs (adalimumab, etanercept, infliximab, golimumab, certolizumab) and Other targets (abatacept, rituximab, sarilumab, tocilizumab). Clinical data, duration of treatment and EULAR response were collected from each patient. The data were analyzed with descriptive, bivariate statistics and survival analysis adjusted for age, sex, FR, erosions and duration of the disease.

Results: Data were collected from 332 patients (table 1). Patients treated with other target bDMARDs were mostly female, with higher activity, shorter disease duration, and treated without MTX.b Survival graphs showed that regardless of the target chosen as fist bDMARD, EULAR response rates and persistence to the drug were similar.

Table 1.

\begin{tabular}{lcccc}
\hline Variable & $\begin{array}{c}\text { TNF inhibitors } \\
\mathrm{n}=194\end{array}$ & $\begin{array}{c}\text { Other targets } \\
\mathrm{n}=138\end{array}$ & $\begin{array}{c}\text { Total } \\
\mathrm{n}=332\end{array}$ & $\mathrm{p}$ \\
\hline & $\mathrm{n}(\%)$ & $\mathrm{n}(\%)$ & $\mathrm{n}(\%)$ & 0.02 \\
\hline Female & $142(73)$ & $115(83)$ & $257(77)$ & 0.2 \\
FR + & $163(82)$ & $121(88)$ & $284(86)$ & 0.6 \\
ACPA + & $125(63)$ & $84(61)$ & $209(63)$ & 0.9 \\
Erosions & $177(89)$ & $80(58)$ & $257(77)$ & 0.01 \\
Concomitant MTX & $153(77)$ & $62(47)$ & $215(65)$ & 0.003 \\
EULAR response & & & & \\
Good & $103(77)$ & $67(71)$ & $170(75)$ & 0.2 \\
Moderate & $24(18)$ & $16(17)$ & $40(17)$ & \\
No & $7(5)$ & $11(11)$ & $18(8)$ & \\
Age (years) & Mean $\pm \mathrm{SD}$ & Mean $\pm \mathrm{SD}$ & $\mathrm{Mean} \pm \mathrm{SD}$ & \\
Evolution of RA (years) & $55.7 \pm 13.3$ & $57.6 \pm 11.9$ & $56.5 \pm 12.7$ & 0.1 \\
Persistence (months) & $9.6 \pm 10.2$ & $7.5 \pm 7.5$ & $8.7 \pm 9.2$ & 0.04 \\
DAS28VSG4V basal & $19.3 \pm 20.5$ & $16.07 \pm 15.11$ & $17.5 \pm 18.5$ & 0.04 \\
DAS28VSG4V final & $5.02 \pm 1.5$ & $5.59 \pm 1.03$ & $5.25 \pm 1.3$ & 0.001 \\
\hline
\end{tabular}

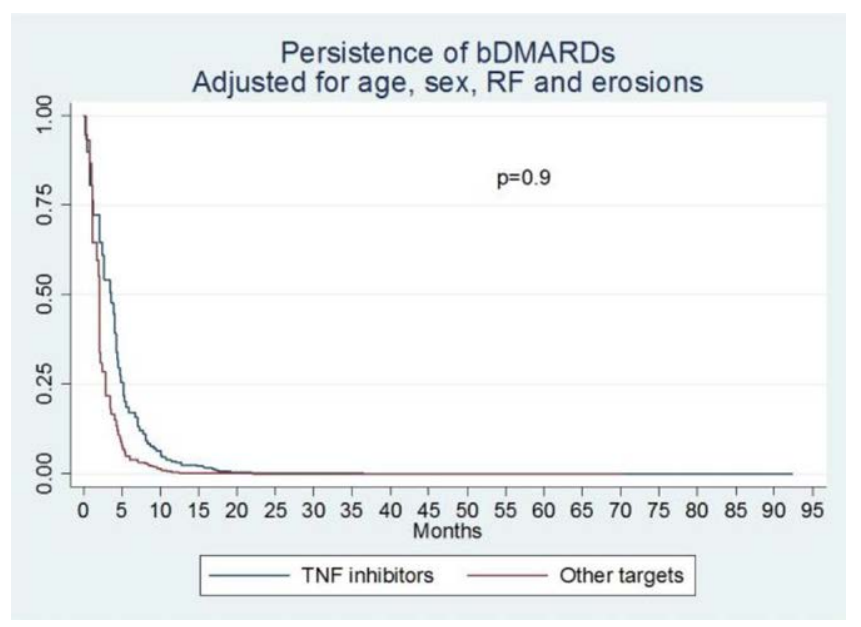

Conclusion: Patients receiving Anti-TNF vs bDMARD with other mechanisms of action have clinical differences. However, the response and persistence to the drug are similar, perhaps due to the implementation of the correct T2T strategy.

Disclosure of Interests: None declared

DOI: 10.1136/annrheumdis-2021-eular.3920

\section{AB0240 1 PREDICTORS OF RESPONSE TO BIOLOGIC AGENTS IN RHEUMATOID ARTHRITIS}

K. Saadaoui ${ }^{1}$, H. Sahli ${ }^{1}$, S. Jemmali ${ }^{1}$, S. Boussaid ${ }^{1}$, S. Rekik ${ }^{1}$, E. Cheour ${ }^{1}$, M. Elleuch'. 'La Rabta Hospital, Rheumatology, Tunis, Tunisia

Background: In rheumatoid arthritis (RA), the 'treat-to-target' therapeutic approach imposes rigorous control of disease activity. Although biological agents have been shown to be effective, these therapies fail sometimes to achieve therapeutic goals.

Objectives: In this study we tried to determine predictive factors of good therapeutic response to biologic disease-modifying antirheumatic drugs (bDMARD).

Methods: This is a retrospective study including 374 Tunisian patients who received their first biotherapy between 2014 and 2016. Categorical variables were reported in numbers and percentages, while quantitative variables were expressed by mean with standard deviations. The univariate analysis was performed using the student t-test or the Chi2 test. Multivariate analysis was performed by binary logistic regression.

Results: Average age of our cohort was $55 \pm 12.5$ years with a female predominance of $87.2 \%$. The average duration of RA was $11.7 \pm 6.7$ years. Rheumatoid factors were positive in $79 \%$ and ACPA were positive in $72 \%$ of cases. After the introduction of biotherapy, low disease activity (LDA) or remission was achieved in $55 \%$ of cases (206 patients).

No statistically significant difference between biotherapy responder and non-responder groups for age (55.7 vs. 54.7 years; $p=0.44)$, gender (Female: $86.5 \%$ vs. $88.7 \% ; p=0.08$ ) and disease duration (12 years vs. 11.4 years; $p=$ $0.41)$. A significant difference between the two groups was found for the positivity of rheumatoid factors $(76.4 \%$ vs. $88.9 \% ; p=0.004)$, methotrexate's association (65\% vs. $53.4 \%$; $p=0.02)$ and corticosteroids' use (50\% vs. $66.5 \%$; $<0.001)$.

Positive predictive factors of remission or LDA by biotherapy were female sex (Odds Ratio $=2.2 ; p=0.026$ ), presence of rheumatoid factors (Odds Ratio = $2.64 ; p=0.001$ ), association with methotrexate (Odds Ratio $=1.69 ; p=0.028$ ). Whereas, corticosteroid use $(O R=0.41 ; p<10-3)$ was a negative predictor of disease control by bDMARDs.

Conclusion: Achieving LDA low level or even remission is currently achievable with biological treatments. Certain factors need to be studied in order to optimize RA treatment and adapt the right bDMARD for each patient.

Disclosure of Interests: None declared

DOI: 10.1136/annrheumdis-2021-eular.3928 